\title{
UNA PROPUESTA DE FILOSOFÍA DEL DERECHO PARA EL MUNDO LATINO*
}

\author{
Manuel Atienza \\ Universidad de Alicante
}

RESUMEN. A partir de una determinada concepción del Derecho y de cierto diagnóstico sobre la situación de la filosofía del Derecho en los países latinos, se propone un modelo de elaboración teórica basado en la combinación de tres ingredientes: método analítico, objetivismo ético e implantación social.

Palabras clave: Filosofía del Derecho, países latinos.

ABSTRACT. Starting from a particular legal conception and a certain diagnosis about the current situation of legal philosophy in Latin countries, the author proposes a model of legal theory based on the combination of three ingredients: analytical method, moral objectivism and social implantation.

Keywords: Legal Philosophy, Latin countries.

* El texto reproduce la última parte de mi intervención en el Debate sobre el futuro del positivismo jurídi$c o$, que tuvo lugar (el otro contendiente era Eugenio BulYGIN) en el $23^{\circ}$ congreso de la IVR, celebrado en Cracovia en agosto de 2007. 


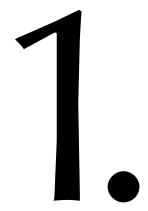

Si el Derecho — como alguna vez se ha escrito- es «una gran acción colectiva que transcurre en el tiempo», una práctica social, entonces la teoría del Derecho tiene, de alguna manera, que formar parte de esa práctica. Una consecuencia de ello es que el teórico del Derecho no puede ser ajeno a los valores de esa práctica, ni puede tampoco concebir su participación en la misma en términos puramente individuales. Lo que debería guiar nuestro trabajo, en definitiva, no es el afán de originalidad, sino de participar cooperativamente con otros en la mejora de esa práctica.

2. La elaboración de una teoría del Derecho completamente general, válida para cualquier sistema jurídico, es una empresa de valor limitado. Pero, además, no es nada obvio que la teoría jurídica al uso, el paradigma anglo-americano dominante (positivista o no), sea verdaderamente general. Por eso, ante el riesgo cierto de que la globalización en la teoría del Derecho responda más bien a lo que se ha llamado la «globalización de un localismo», podría ser de interés desarrollar teorías del Derecho — digamos«regionales», de acuerdo con los diversos círculos de cultura hoy existentes. El multilateralismo parece una estrategia deseable, y no sólo en el ámbito de la política internacional.

3. Los países latinos, de Europa y de América, constituyen uno de esos círculos culturales. Aunque con niveles de desarrollo económico, político, científico, tecnológico, etc., diferentes, esos países son sumamente afines desde el punto de vista de sus sistemas jurídicos y de sus lenguas, poseen una rica tradición de pensamiento jurídico y en todos ellos el Estado constitucional opera como un ideal regulativo para el desarrollo del Derecho y de la cultura jurídica. En muchos de esos países la filosofía del Derecho ocupa hoy un lugar académicamente destacado, lo que explica que exista un buen número de cultivadores de la disciplina con un alto nivel de competencia «técnica». ¿Cómo explicar entonces que la producción iusfilosófica se limite en buena medida a comentar o discutir ideas y teorías surgidas en otros ámbitos culturales y destinadas también muchas veces a tratar con problemas característicos de esos otros ámbitos?

4. Lo anterior no es una invitación al localismo en la teoría del Derecho, sino a distinguir lo pura o fundamentalmente local y lo que tiene —o puede tener- un valor genuinamente general o universal (en relación, al menos, con el universo del Estado constitucional). Las teorías iusfilosóficas de ámbito regional podrían configurar una útil mediación ente lo local y lo universal y contribuir así a una globalización más equilibrada en la teoría del Derecho.

5. La filosofía del Derecho no es un género retórico, pero una forma equivocada de practicar la teoría jurídica consiste en desentenderse de quiénes son los destinatarios de los escritos iusfilosóficos y de quiénes pueden hacer uso de las ideas que se encuentran en ellos. Quizás no tenga sentido producir obras destinadas únicamente a otros filósofos del Derecho, y menos aún cuando sus destinatarios directos parecerían ser intelectuales a los que todo lo que se genera fuera de su ámbito cultural les es ajeno.

6. Otro error, que frecuentemente va de la mano del anterior, es el de olvidar que una teoría del Derecho sólo merece la pena si se ocupa de problemas relevantes y que 
esa relevancia viene fijada por los intereses de la comunidad jurídica ampliamente entendida. Además de algún otro factor de carácter exógeno, no es absurdo pensar que la falta de atención a los problemas y a los destinatarios puede constituir la principal explicación de la insatisfactoria situación de la filosofía del Derecho en los países latinos: un (al menos en muchos casos) alto nivel de sofisticación técnica y una (en general) escasa influencia en la cultura jurídica y en la práctica del Derecho de sus respectivos países.

7. Un modelo de teoría del Derecho pragmáticamente útil y culturalmente viable en nuestros países bien podría consistir en combinar estos tres ingredientes: método analítico, objetivismo moral e implantación social. Cada uno de ellos está especialmente vinculado a una de las grandes concepciones del Derecho bajo las cuales se suele clasificar, entre nosotros, a los filósofos del Derecho: el positivismo jurídico, el iusnaturalismo y la teoría crítica del Derecho.

8. Positivismo jurídico y filosofía analítica no son, obviamente, términos sinónimos pero, dada la estrecha vinculación existente entre ambos, es razonable considerar que el método analítico es uno de los aspectos más valiosos que el positivismo jurídico puede dejar como herencia a la cultura jurídica. Ese método suele cifrarse en el uso y aceptación de ciertas distinciones (por ejemplo, entre enunciados descriptivos y prescriptivos, o entre explicar y justificar) que, por lo demás, no deberían entenderse en un sentido rígido: entre lo descriptivo y lo prescriptivo pueden existir «puentes» y explicar una decisión puede contribuir notablemente a su justificación.

9. Algo parecido puede decirse de la relación entre el iusnaturalismo y el objetivismo moral y la unidad de la razón práctica, si bien la manera más adecuada de sostener estas dos últimas tesis no consiste en recurrir al Derecho natural, sino a alguna forma de procedimentalismo o constructivismo moral. En todo caso, las dos principales razones para rechazar el no cognoscitivismo ético (y el relativismo, pero obviamente no como posición de ética descriptiva) son: 1) no permite reconstruir aspectos importantes de la práctica jurídica (en particular, de la justificación de las decisiones judiciales); 2) es autofrustrante. La alternativa debería ser un objetivismo moral (mínimo) que, frente al relativismo, defienda la tesis de que los juicios morales incorporan una pretensión de corrección y, frente al absolutismo, la de que los juicios morales (como los de los tribunales de última instancia) incorporan razones últimas (en el razonamiento práctico), pero abiertas a la crítica y, por tanto, falibles.

10. Los aspectos más valiosos de las teorías críticas del Derecho giran en torno a la necesidad de insertar el Derecho (y la teoría del Derecho) en el medio social y plantearse su potencial de transformación social. Esa concepción (o una cierta manera de entenderla) muestra así la necesidad de que la teoría del Derecho incorpore ciertas categorías que generalmente quedan fuera del análisis (conflicto, trabajo, poder, necesidad social), asuma el carácter histórico del Derecho y de las categorías jurídicas y preste atención a los elementos desigualitarios e ideológicos del Derecho (también de los Derechos del Estado constitucional). 